how extensively innovation depends on R \& D, especially on long-term research. But the expertise in universities has not been used as extensively as possible to support industrial innovation. The NSF programme has already shown successes, and it is time to expand this effort," says Dr Press.

Congressional response to the package, promised since last April, has been lukewarm. Some proposals, such as the setting up of "generic technology centres" and the introduction of uniform patent policy, have been generally welcomed; indeed many are already part of legislative proposals currently before Congress.

At a Senate hearing last week, however, several Congressmen criticised the package for not including any tax incentives related to $\mathbf{R} \& \mathbf{D}$ expenditures. Administration officials replied that these would come later, as part of a complete set of tax reforms; and Dr Jordan Baruch of the Commerce Department said that tax incentives might not be a sharp enough instrument to attack such a complex issue.

Senator Adlai Stevenson criticised the package for lacking imagination. "It is a first step, but I am not convinced that the Executive Branch has got the guts to take the next ones needed to reach a rational technology policy" he said. Mr Stevenson quoted in particular Japan's recently announced plans to stimulate government support across a wide range of technological areas, from ocean mining to integrated circuits.

"For 25 years the question of innovation has been around," replied Dr Press. "For the first time the President has come forward with definite proposals; I think this is an important step. And US industrial leaders that I have spoken to would not want to touch what the Japanese are doing with a ten-foot pole."

\title{
Soviets announce build-up to fusion power
}

RECENT Soviet developments in energy were conspicuous by their absence from the agenda of last week's UK-Soviet energy symposium in Moscow. To some extext, this was to be expected, since the prime aim of the symposium was to explore areas of possible cooperation in the near future. Nevertheless, even in his exposition of the long-term "second stage" of the new Soviet energy "strategy", the Minister of Power and Electrification, Peter S. Neporozhnyy, made no allusion at all to the Soviet Union's latest step in power generation - the start-up of the first module of the Angara-5 fusion generator.

This is all the more remarkable since the demonstration run of the Angara-5 module, early in October, was given considerable media coverage for both home and foreign consumption. The Angara-5 is an electron beam device, the name, according to Pravda, signifying the five tributaries (the beams) which flow into lake Baikal (the tritium/deuterium target), and issue thence as the mighty Angara river (the energy produced). Last month's test of the module was carried out at the Kurchatov Atomic Energy Institute; according to Valerii Legasov, the Deputy Director, after "through experiments" have been carried out with each of the 48 modules, a "demonstration" Angara-5 will be built at the institute's test site.

No indication, has so far been given of when the break even point may be expected, although Moscow radio's "World Service" suggested that the first power plants based on Angara-5 will be built by the end of the century. At all events, practical use of the Angara-5 lies too far in the future to merit a place in Neporozhnyy's "strategy", although his outline of the "second stage" did include some references to MHD and fusion generation.

In MHD, he said, work would go forward on improving conversion efficiency and hinted that "energy and magnetic field parameters close to commercial" were already within reach on one experimental device. Fusion research, he said, would continue using both Tokamak and laser techniques. Already plasma temperatures only 4-5 times less

than those required for sustained reaction, he said, had been attained.

The majority of the symposium, however, was devoted to the first stage of the strategy; development of the coal industry, including low grade coals to be used in generating stations close to the mines, expansion of the Siberian hydroelectric network and the phasing out of oil and gas-fired power stations.

Although the Soviet planners still claim ample reserves of oil and gas, they are now ready to admit that these lie in increasingly remote and extreme terrains, and that exploitation costs will become increasingly expensive. Indeed, for the firt time, they are prepared to admit small and temporary stortfalls in production. In the not too far future, the Soviet participants in the symposium agreed, oil will have to be reserved for oil-specific industries transport and petrochemicals.

Nuclear generation will to a large extent replace oil in the power sector. Although the extension of the Union-wide "supergrid" of $1500 \mathrm{~V}$ DC transmission lines should, theoretically, allow power

\section{Hungarian reactor to be made 'safe'}

CONSTRUCTION of the Paks nuclear power station, which should supply one third of Hungary's present peak power demand, is at last on schedule. Last year, the station, whose construction had been running late since 1975, was the subject of special resolutions by the Council of Ministers and the Party Politburo. A new management system was set up, with government commissioners working on the site. Shortly afterwards, building operations were reported to have "speeded up considerably', although the workforce of 5200 is still insufficient and more managerial changes are envisaged if the original schedule is to be maintained.

This acceleration, however, has not been achieved at the cost of safety. Out of the 60,000 million forints ( $£ 1,500$ million) which the station will cost, 12,000 million $(20 \%)$ will be spent on safety measures.

The Hungarian planners are in a somewhat delicate position as regards stations to be sited anywhere, the old paradox of the Soviet energy map $(80 \%$ of resources east of the Urals, $80 \%$ of consumption west of the Urals) is being perpetuated in the siting of future nuclear power stations, close to the consumers.

Hardly a mention, even in informal discussions, was made during the symposium of Academician Sollezhal's recent proposals for nuclear generating "complexes" in Siberia. The safety and ecological aspects raised by Dollezhal' were barely alluded to, and the plans for nuclear "boiler houses" for district heating in major cities were given great prominence; with, perhaps, one small difference.

Until now, Soviet commentators have suggested that the nuclear boiler houses would be situated in the suburbs of the cities, with a "safety-zone" of some 1-2 km around them, reserved for industrial and leisure use (but not housing). Now, however, according to Neporozhnyy, the boiler houses may be further away transmission of the hot water for up to $50 \mathrm{~km}$, he said, is reckoned to be "economic".

Vera Rich

safety. The country is small, with no convenient expanse of empty land in which to site a reactor. Moreover, Austrian TV reaches considerable areas of Hungary, and although any evidence on the subject can only be anecdotal, there is good reason to believe that the population at large was considerably perturbed by the "antinuclear" verdict of the Austrian referendum earlier this year.

Perhaps for this reason, a recent Budapest TV programme describing the Paks station paid especial attention to its safety precautions. "Triple walls", said the commentator, separate radioactive materials from the environment. The outermost of these walls, from his description, is simply a steel and concrete containment vessel - of the type, until recently, dismissed by Soviet planners (who are intimately involved in any Comecon nuclear power station) as a Western capitalist ploy to inflate costs. 